\title{
THE PRESENCE OF ANTIAUTONOMIC MEMBRANE RECEPTOR ANTIBODIES DO NOT CORRELATE WITH BRAIN LESIONS IN CHAGAS' DISEASE
}

\author{
Marco O. Py', Leonardo Maciel ${ }^{2}$, Roberto C. Pedrosa ${ }^{3}$, Jose H. M. Nascimento ${ }^{2}$,Emiliano Medei ${ }^{2}$
}

\begin{abstract}
We previously demonstrated correlation between parasympathetic dysfunction and brain white matter lesions in chronic chagasic patients. Objective: To correlate serum functional circulating antibodies with beta adrenergic (Ab- $\beta$ ), muscarinic (Ab-M) or muscarinic and beta adrenergic (Ab-M $\beta$ ) activity, the autonomic system function and brain lesions in chronic chagasic patients. Method: In fifteen consecutive chagasic patients, the autonomic nervous system was evaluated and brain magnetic resonance imaging (MRI) was performed. The sera of all patients were tested to the presence of circulating functional antibodies. Results: Sera from 11 of 15 chronic chagasic patients had some activity (Ab- $\beta$ : 7; Ab-M: 1; Ab-M $\beta$ : 3); however, there was no significant correlation between the presence of antibodies and the autonomic system function or the presence of hyperintensities in MRI. Conclusion: The mechanism involved in the genesis of hyperintense lesions seen in brain MRI of chronic chagasic patients is still unresolved, although apparently related to parasympathetic dysfunction.
\end{abstract}

KEY WORDS: Chagas' disease, American trypanosomiasis, autonomic dysfunction, antibodies, magnetic resonance imaging, hyperintense lesions.

A presença de anticorpos anti-autonômicos não se correlaciona a lesões cerebrais na doença de Chagas

Resumo - A correlação entre disfunção parassimpática e lesões de substância branca cerebral em pacientes chagásicos já foi previamente demonstrada. Objetivo: Correlacionar a presença de anticorpos circulantes funcionais com atividade beta-adrenérgica (Ab- $\beta$ ), muscarínica ( $A b-M)$ ou muscarínica e beta adrenérgica (Ab-M $\beta$ ), a presença de disautonomia e lesões de substância branca cerebral em pacientes chagásicos crônicos. Método: Em quinze pacientes chagásicos consecutivos, foram realizados a avaliação do sistema nervoso autônomo e ressonância magnética (RM) do crânio. $O$ soro dos pacientes foi testado para a presença de anticorpos funcionais circulantes. Resultados: $O$ soro de 11 dos 15 pacientes chagásicos apresentou alguma atividade ( $A b-\beta: 7 ; A b-M: 1 ; A b-M \beta$ : 3); porém não houve correlação significativa entre a presença de anticorpos circulantes e disautonomia ou de hiperintensidades à RM. Conclusão: $O$ mecanismo envolvido na gênese das lesões hiperintensas à RM do crânio dos pacientes chagásicos crônicos não está esclarecida ainda, apesar de aparentemente relacionada à disfunção parassimpática.

PALAVRAS-CHAVE: doença de Chagas, tripanossomíase americana, disfunção autonômica, anticorpos, ressonância magnética, lesões hiperintensas.

Chagas' disease (American trypanosomiasis) is endemic in Latin America and is still an important public health problem in Brazil. It has been associated with neurological alterations ever since it was first described'. In the chronic phase, cerebrovascular disease is a recognized cardioem- bolic complication in patients with Chagas' disease even in the absence of cardiomyopathy or cardiac arrhythmias ${ }^{2}$. Other stroke mechanisms are described with some authors suggesting an association between Trypanosome infection itself and stroke ${ }^{3}$. Other authors suggest that au-

\footnotetext{
'Instituto de Neurologia Deolindo Couto and Hospital Universitario Clementino Fraga Filho, Universidade do Brasil, Rio de Janeiro RJ, Brazil; ${ }^{2}$ Instituto de Biofísica Carlos Chagas Filho, Universidade do Brasil, Rio de Janeiro RJ, Brazil; ${ }^{3}$ Hospital Universitário Clementino Fraga Filho, Universidade do Brasil, Rio de Janeiro RJ, Brazil. The present research was supported by grants from the National Research Council (CNPq-Brasil) and the Rio de Janeiro State Research Agency (FAPERJ).
}

Received 13 March 2009, received in final form 9 May 2009. Accepted 11 June 2009.

Dr. Marco O. Py - Rua Marechal Mascarenhas de Moraes 191/408 - 22030-040 Rio de Janeiro RJ - Brasil. E-mail: marcopy@uninet.com.br 
tonomic dysfunction might be responsible for cerebrovascular disease as it may induce endothelial dysfunction leading to vasoconstriction, cerebral vascular spasms and, ultimately, a clinically defined stroke ${ }^{4}$. Considering that the pathogenesis of the autonomic nervous system dysfunction has an autoimmune basis ${ }^{5}$, it would be fair to postulate that autonomic dysfunction such as observed even in the early phase of Chagas' disease might be consequent to autoreactive antibodies. These antiautonomic membrane receptor antibodies are able to activate, either, beta adrenergic- $(A b-\beta)^{6}$, muscarinic (Ab-M) or both, muscarinic and beta adrenergic (Ab-M $\beta$ ) autonomic receptors ${ }^{7}$. In addition, Ribeiro et al. has shown strong correlation between the presence of $A b-M$ and abnormal vagal modulation in chronic chagasic patients ${ }^{8}$.

White matter hyperintense lesions were previously described by the authors in $53 \%$ of brain magnetic resonance imaging (MRI) of chronic chagasic patients, even in early phase of the disease (without cardiomyopathy). These lesions significantly correlated to parasympathetic dysfunction, evaluated by sinus arrhythmia test ${ }^{9}$. In contrast, white matter hyperintense lesions are described in up to $13 \%$ of general population ${ }^{10}$. Other authors also found white matter lesions in brain MRI of early phase Chagas' disease patients, associated with unspecific electroencephalographic disorders" ${ }^{11}$. Aging and arterial hypertension have been related to these lesions ${ }^{10}$, but correlation between them and strokes are still disputed ${ }^{12-14}$.

The objective of this study was to test the correlation between the presence of functional active circulating antibodies ( $A b-\beta, A b-M$ and $A b-M \beta$ ), autonomic system dysfunction and white matter lesions seen in brain MRI of chronic chagasic patients.

\section{METHOD}

This is a prospective study, carried out from 2006 to 2008. The study population comprises patients evaluated at the Chagas' disease outpatient clinic from the University Hospital of the Federal University of Rio de Janeiro, Brazil. Consecutive patients with chronic Chagas' disease in early phase were considered for inclusion. All patients were in phase IA in the Modified Los Andes classification ${ }^{15,16}$, which means no cardiomyopathy or cardiac arrhythmias. The local ethics committee (Clementino Fraga Filho University Hospital of the Federal University of Rio de Janeiro) approved the protocol and written informed consent was obtained from each patient.

The diagnosis of Chagas' disease required at least two positive standard serologic tests for antibodies against Trypanosoma cruzi (indirect immunofluorescence, indirect hemagglutination, and/or enzyme-linked immunosorbent assay).

Exclusion criteria were: age over 70 years; ischemic heart disease; association of any other heart disease; previous stroke, arterial hypertension, diabetes mellitus, renal failure; chronic ob- structive pulmonary disease; smoking, alcoholism and any other important systemic disease. Patients who have received specific treatment for chagasic infection were also excluded.

Beta-blockers (as carvedilol) and calcium channel blockers were transiently discontinued (five half-lives) before blood samples were drawn.

In order to evaluate autonomic system function, cardiac frequency variability was analyzed on resting electrocardiogram (ECG). The signals were collected and stored in a personal computer (processing software Biopotentials Captation System ${ }^{17}$, which allows the examiner to eliminate QRS complexes with artifacts), to measure the cardiac frequency variability in the time and frequency domains: after a 20-minute resting period in supine position, the patients were submitted to the respiratory sinus arrhythmia maneuver, with a controlled respiratory rate of 12 incursions per minute (along 2 minutes), to promote a vagal response ${ }^{18,19}$. Variables evaluated in the time domain included the proportion of consecutive cardiac beats with a difference of 50 milliseconds or more between the consecutive beats (pNN50); and the mean square root of the sum of squares of the differences between consecutive cycles (rMSSD). Both variables give estimates of cardiac parasympathetic function. Frequency domain (spectral analysis) was evaluated by the ratio between low frequency (LF) components of the cardiac cycle (representing the sympathetic component) and high frequency (HF) components (parasympathetic component): the LF/HF represents the relationship between sympathetic and parasympathetic balance ${ }^{20}$. $\mathrm{LF}$ and $\mathrm{HF}$ were measured in normalized units, which represent the relative value of each power component in proportion to the total power. As there are no published parameters of normality in Chagas' disease, cardiac frequency variability was analyzed as a continuous variable, instead of using "normal" and "abnormal" dichotomization.

MRI (Elscint Prestige, 2.0 Tesla) was performed using T1, T2 and FLAIR sequences in all subjects. For this paper we considered only the presence or absence of white matter hyperintense lesions, evaluated by an expert neuroradiologist.

\section{Isolated heart and sera characterization}

The method for ECG recording from isolated rabbit hearts has been described in detail ${ }^{7}$. In brief, young rabbits weighing 1.5 to $2.0 \mathrm{~kg}$ were killed by cervical dislocation, and their hearts were rapidly removed and cannulated through the aorta for continuous perfusion of the coronary circulation with Tyrode solution (mmol/L): $\mathrm{NaCl}, 127 ; \mathrm{KCl}, 2.7 ; \mathrm{NaHCO} 3,12 ; \mathrm{MgCl} 2,0.5 ;$ glucose, 10; and $\mathrm{CaCl} 2,2.7 ; \mathrm{pH} 7.2$ at $36^{\circ} \mathrm{C} \pm 0.2^{\circ} \mathrm{C}$. The hearts were immersed in warmed Tyrode solution in a water-jacketed glass flask; three glass electrodes filled with $1 \mathrm{~mol} / \mathrm{L} \mathrm{NaCl}$ were positioned inside the flask to obtain optimal ECG recordings. Two electrodes were connected to the differential input of a high gain amplifier (A-M System, USA) and the third was connected to ground. The experimental protocol consisted of control recordings for 15 to $20 \mathrm{~min}$ in Tyrode's solution, a 30 min perfu- 
sion with Tyrode solution containing serum $(1: 100 \mathrm{v} / \mathrm{v})$ from the chagasic patients, and return to Tyrode solution (washout). The ECG was continuously recorded with the data acquisition software Axoscope (Axon Instruments, USA). Experiments were carried out only if no significant change in the ECG parameters was observed for the 15 to 20 min duration of the control recordings. The ECG analysis included RR and PR interval and presence of atrioventricular conduction block.

The sera characterization as beta-adrenergic, muscarinic, both beta and muscarinic effect or non functional (Ab-NF) was made by ECG recordings in isolated rabbit hearts ${ }^{7}$. In this preparation, heart rate response to sera was assessed during spontaneous rhythm, to divide the sera of patients into four groups and to assess the functional activity of the antibodies. A given patient's serum was characterized as $A b-\beta$ only when the serum was able to increase spontaneous heart rate by at least $10 \%$ within 30 min of initial perfusion of the isolated rabbit heart, and this effect was abolished by a beta adrenergic antagonist ( $1 \mu \mathrm{M}$ atenolol). On the other hand, chronic chagasic patient's serum was characterized as $A b-M$ when the serum decreased the heart rate by at least $10 \%$ within $30 \mathrm{~min}$, and this effect was abolished by a muscarinic antagonist (1 $\mu \mathrm{M}$ atropine). When the sera increased together heart rate and PR interval, at least $10 \%$ within 30 min of sera perfusion, they were considered Ab-M $\beta$. Ab-NF was considered when the serum did not alter spontaneous heart rate.

Sera from healthy orthopedic surgery patients without Chagas infection or history of cardiac disease were also used (reference sera). Independent experiments were performed to test each serum. When necessary, to confirm the serum effect, the experiment was repeated in a new heart, in the presence of adrenergic or muscarinic antagonist, atenolol (1 $\mu \mathrm{M})$ and atropine $(1 \mu \mathrm{M})$ respectively.

\section{Statistical analysis}

All variables were correlated with each other using Spearman correlation coefficient and Mann-Whitney test. Statistical analysis was made with SPSS 11.0 software. Statistical significance was estimated by Student $t$ test or one way ANOVA coupled with Newman-Keuls. Difference was considered significant at $\mathrm{p}<0.05$.

\section{RESULTS}

Fifteen patients (eight men) with mean age 54.06 $( \pm 11.31)$ were enrolled. Eight patients $(53.3 \%)$ presented white matter hyperintense lesions in brain MRI (Fig 1).

From 15 chronic chagasic patients sera tested in isolated rabbit hearts, seven showed adrenergic activity, as shown in Figure 2A. These sera have significantly and reversibly shorted the RR interval from $1257 \pm 38.8 \mathrm{~ms}$ in control condition to $931 \pm 23.5 \mathrm{~ms}$ under sera perfusion and returned to $1228 \pm 41.2 \mathrm{~ms}$ after washout (One-way anal$y$ sis of variance $p<0.0001$ control and washout vs $A b-\beta$ ). The adrenergic sera activity, in other experiment, was

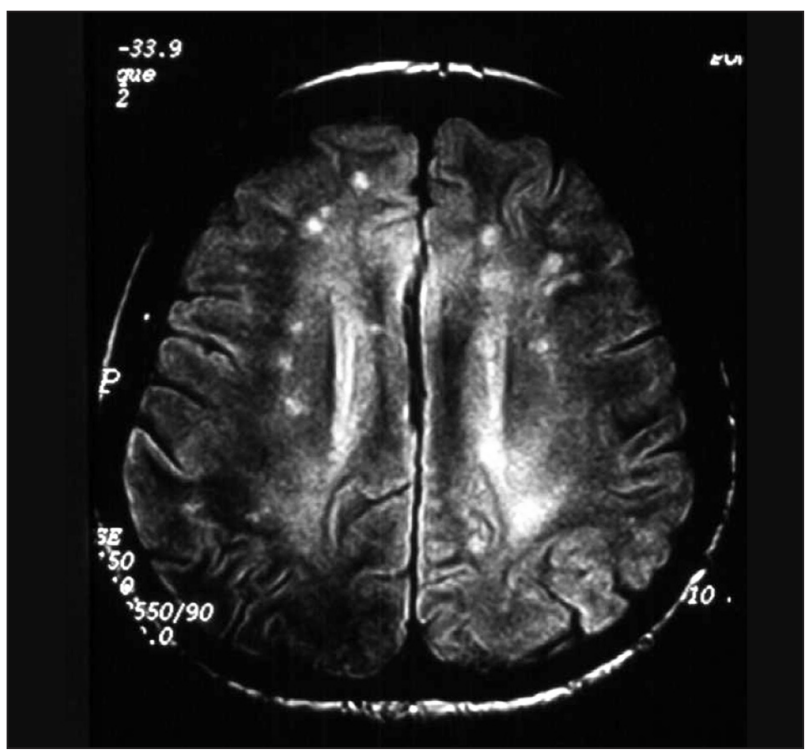

Fig 1. Brain MRI (FLAIR) showing white matter hyperintense lesions in a chronic chagasic patient.

A

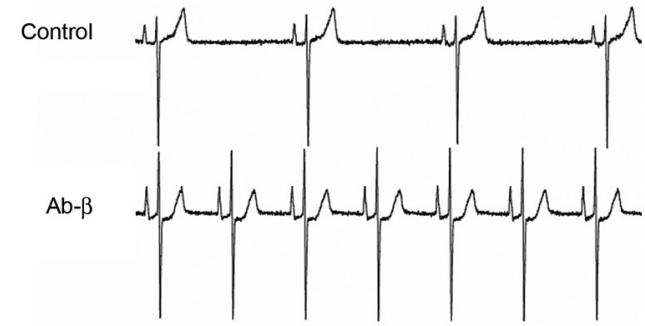

Washout

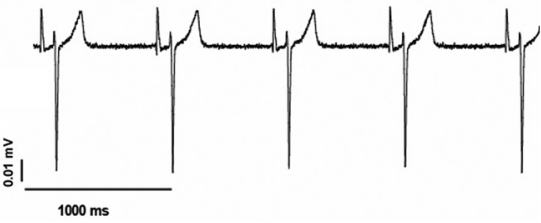

B

Control

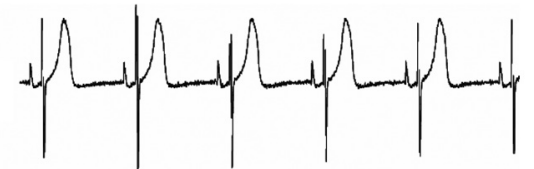

Ab- $\beta+$ Atenolol

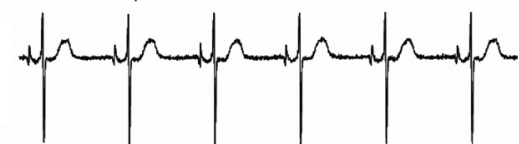

Washout

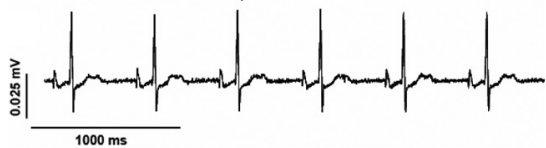

Fig 2. Adrenergic activity of serum from chronic chagasic patient on isolated rabbit heart. [A] Control condition in the upper traces; in the middle, traces were obtained in the presence of serum $(1: 100 \mathrm{v} / \mathrm{V})$, showing tachycardia. The effect was reversibly, as shown in the lower traces. $[B]$ The experiment was made in a new heart in the presence of the beta-1 antagonist atenolol (1 $\mu \mathrm{M})$. In this condition, no changes were observed, suggesting the adrenergic activity of this serum. 


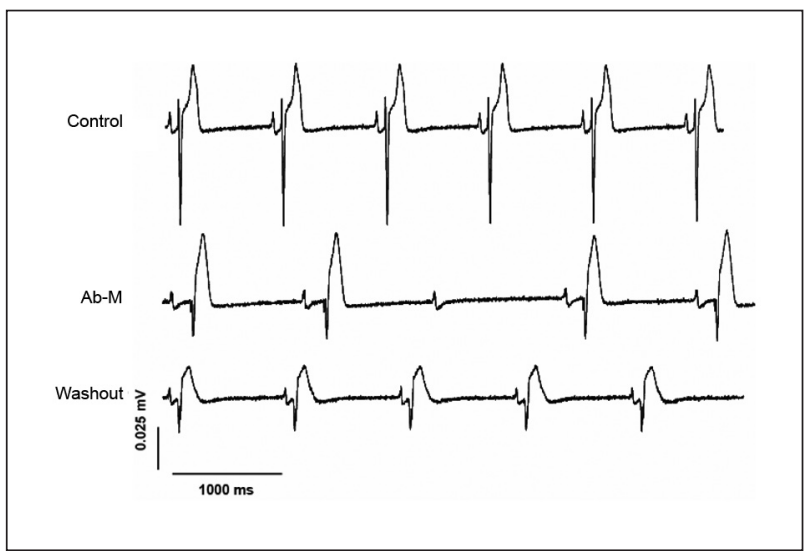

Fig 3. Muscarinic activity of serum from chronic chagasic patient on isolated rabbit heart. Control condition is in upper panel; and the presence of serum $(1: 100 \mathrm{~V} / \mathrm{V})$ is in the middle, showing atrioventricular block, characterized by several non-conducting $P$ waves (not followed by the $Q R S$ complex), PR and RR intervals longer than control condition, consequent to bradycardia induced by muscarinic activity. All of these effects were reversible in the washout condition, lower panel.

prevented by the perfusion of the beta- 1 antagonist atenolol (Fig 2B). One serum was characterized as muscarinic (Fig 3). Three sera had both effect, beta-adrenergic and muscarinic, thus, significantly increased PR interval (control=150.2 $\pm 3.5 \mathrm{~ms}$, PR Ab-M 3 : $247.1 \pm 6.1 \mathrm{~ms}$ and washout: $155.6 \pm 3.2 \mathrm{~ms}$; One-way analysis of variance $p<0.0001$, control and washout vs $A b-M \beta$ ) and shortened RR intervals from $1423 \pm 43.5 \mathrm{~ms}$ in control to $1139 \pm 30.5 \mathrm{~ms}$ in $\mathrm{Ab}$ $\mathrm{M} \beta$ and $1506 \pm 49.1 \mathrm{~ms}$ after washout (One-way analysis of variance $p<0.0001$ control and washout vs $A b-M \beta$; Fig 4A). The effect of $A b-M \beta$ on PR interval was completely neutralized when atropine $(1 \mu \mathrm{M})$ was present in the solution, and, as expected, the heart rate was higher than control condition, as shown in Figure 4B. To confirm the presence of the muscarinic activity in this serum, a new experiment was performed in the presence of atenolol $(1 \mu \mathrm{M})$ to inhibit the adrenergic response. Thus, as show the Figure $4 C, A b-M \beta$ in the presence of atenolol diminished heart rate, increased the PR interval and evoked atrioventricular block. All of them are a characteristic of muscarinic effect.

Sera from normal subjects were tested by our group previously, without effect upon the parameters analyzed here $^{21}$. In addition, sera from four patients in the present study had no cardiac activity (Control: $866.7 \pm 38.2$, Ab-NF: $853.7 \pm 35.7 \mathrm{~ms}$ and washout: $868.9 \pm 34 ; \mathrm{p}>0.05)$ in isolated rabbit heart ECGs.

There was a significant correlation between the presence of hyperintense lesions in MRI and: pNN50 ( $<<0.01)$, rMSSD $(p<0.01)$ and LF/HF $(p<0.04)$, as published elsewhere ${ }^{9}$. On the other hand, there was no significant correlation between $\mathrm{pNN} 50$, rMSSD or LF/HF and the presence of the antibodies $A b-\beta, A b-M$ or $A b-M \beta(p>0.05)$.

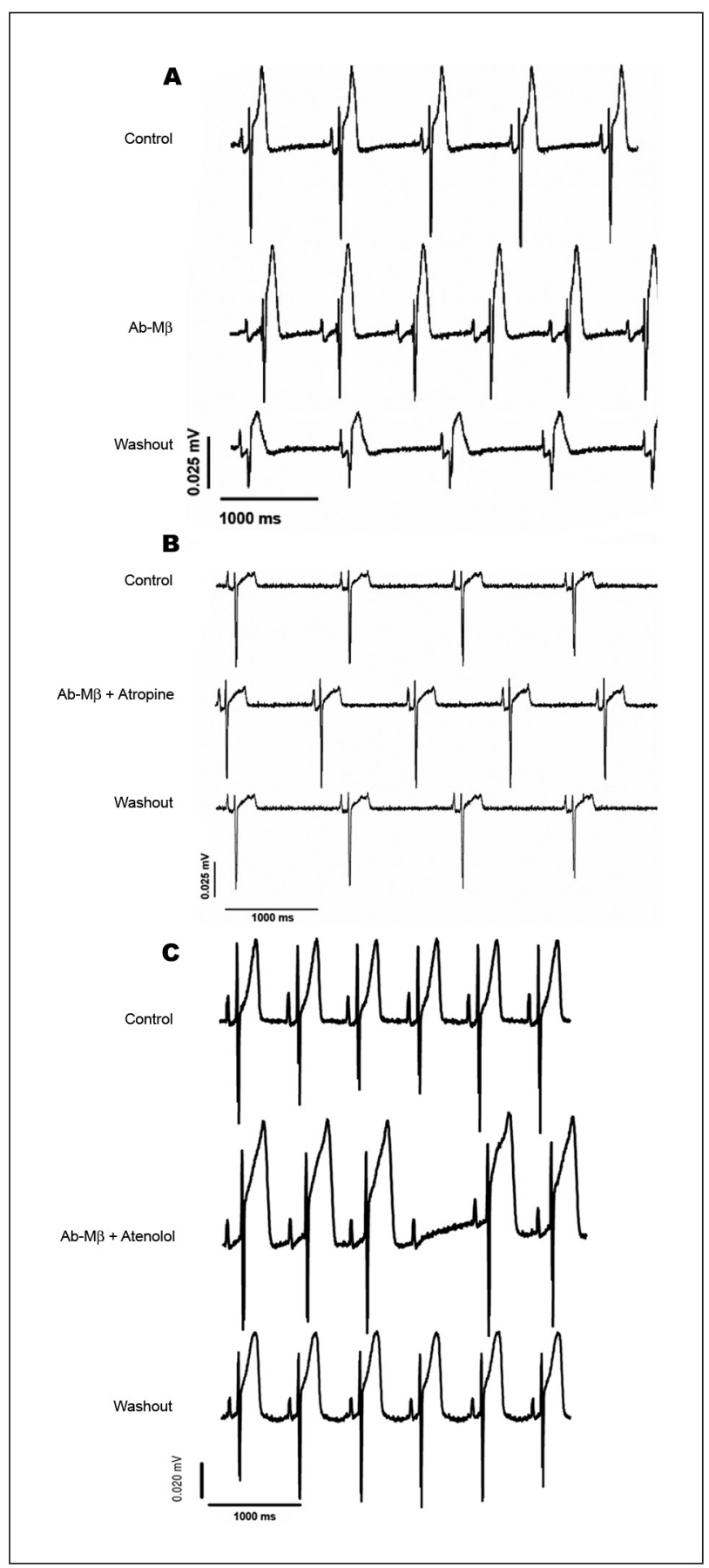

Fig 4. Muscarinic and beta adrenergic effects of serum from chronic chagasic patient on isolated rabbit heart. [A] Control and washout traces represent ECG recorded during Tyrode perfusion, and the middle trace, labeled $A b-M \beta$, was obtained in the presence of a serum that induced an increase of both sinus rate and $P R$ interval, suggesting both adrenergic and muscarinic effect, respectively. $[B]$ The experiment was made in a new heart in the presence of muscarinic antagonist (atropine $1 \mu \mathrm{M}$ ). In the serum condition, more RR intervals appeared compared to control or washout condition, showing adrenergic effect. [C] Atenolol ( $1 \mu \mathrm{M})$ was added during this experiment. Atrioventricular block occurred, characterized by several non-conducting $P$ waves (not followed by the QRS complex). PR and RR intervals are longer than control condition, consequent to the bradycardia induced by muscarinic activity present in the serum. All of these effects were reversible in the washout condition, lower panel. 
There was no significant correlation between the presence of hyperintense lesions in MRI and the presence of the antibodies as well.

In summary, 11 of 15 tested sera had some cardiac effect. But, when we separated the patients by the presence or absence of hyperintense lesions in MRI, we did not find any significant correlation with the characterized sera.

\section{DISCUSSION}

We have previously demonstrated that chronic chagasic patients, even in early stages of the disease, without any cardiac dysfunction, present signs of a parasympathetic disorder that correlate significantly with brain subcortical white matter abnormalities. This was demonstrated by an inverse and significant correlation between lower pNN50 and rMSSD values (representing reduced cardiac frequency variability) and the presence and number of hyperintense lesions in MRI; and by the direct correlation between the LF/HF ratio and the presence of hyperintensities ${ }^{9}$. It shows that parasympathetic dysfunction may enhance the probability to have hyperintense lesions in brain MRI. Additionally, while $53.3 \%$ of our patients presented hyperintensities in MRI, only $13 \%$ subjects present similar lesions in the general population ${ }^{10}$. In agreement with our findings, other authors also demonstrated the presence of white matter lesions in brain MRI of early phase Chagas' disease patients, possibly associated with unspecific electroencephalographic disorders".

Once the reason for that correlation is still unclear, we speculated that Chagas' disease, even in early stages, can promote an imbalance between sympathetic and parasympathetic systems and may promote an intense and sustained cerebral vasoconstriction that cannot be corrected by cerebral vascular autoregulation. On the other hand, we know that chronic chagasic patients often present circulating active functional antibodies that affect isolated rabbit heart, by activation of adrenergic or muscarinic receptors respectively ${ }^{6,7,22,23}$. In fact these antibodies were positively correlated with vagal dysfunction in chronic chagasic patients ${ }^{8}$. So it is reasonable to think that the presence of circulating active functional antibodies could be related to autonomic nervous system dysfunction and brain white matter lesions. In addition, even with vagal dysfunction, our patients do not have any cardiac disorder, in agreement with a previous work of Ribeiro et al. ${ }^{24}$.

Nevertheless, the results in this paper did not confirm this hypothesis. There was no significant correlation between autonomic nervous system function, measured by sinus arrhythmia test, and the presence of antiautonomic membrane receptor antibodies. There was no significant correlation between brain white matter lesions and the presence of the sera active functional antibodies as well.
We conclude that the mechanism involved in the genesis of hyperintense lesions seen in MRI of chronic chagasic patients is still unresolved, although apparently related to parasympathetic dysfunction. More studies are needed to find answers about lesion's physiopathology, which may lead to effective treatment and preventive measures.

\section{REFERENCES}

1. Chagas C. Les formes nerveuses d un nouvelle trypanosomiase: T cruzi inocule par Triatoma megista. Nouv Iconogr Salpetriere 1913;26:1-16.

2. Bestetti R. Stroke in hospital-derived cohort of patients with chronic Chagas disease. Acta Cardiol 2000;55:33-38.

3. Oliveira-Filho J, Viana LC, Vieira-de-Melo RM, et al. Chagas disease is an independent risk factor for stroke: baseline characteristics of a Chagas disease cohort. Stroke 2005;36:2015-2017.

4. Carod-Artal FJ, Vargas AP, Melo M, Horan TA. American trypanosomiasis (Chagas' disease): an unrecognized cause of stroke. J Neurol Neurosurg Psychiatry 2003;74:516-518.

5. Pentreath VW. Trypanosomiasis and the nervous system. Pathology and immunology. Trans R Soc Trop Med Hyg 1995;89:9-15.

6. Borda E, Pascual J, Cossio P, De La Vega M, Arana R, Sterin-Borda L. A circulating IgG in Chagas' disease which binds to beta-adrenoceptors of myocardium and modulates their activity. Clin Exp Immunol 1984;57:679-686

7. Costa PC, Fortes FS, Machado AB, et al. Sera from chronic chagasic patients depress cardiac electrogenesis and conduction. Braz J Med Biol Res 2000;33:439-446

8. Ribeiro AL, Giménez LE, Hernández CC, et al. Early occurrence of anti-muscarinic autoantibodies and abnormal vagal modulation in Chagas disease. Int J Cardiol 2007;117:59-63.

9. Py M, Pedrosa R, Silveira J, Medeiros A, Andre C. Neurological manifestations in Chagas disease without cardiac dysfunction: correlation between dysfunction of the parasympathetic nervous system and white matter lesions in the brain. J Neuroimaging 2008;In press.

10. Culebras A, Kase CS, Masdeu JC, et al. Practice guidelines for the use of imaging in transient ischemic attacks and acute stroke. Stroke 1997; 28:1480-1497.

11. Wackermann PV, Fernandes RMF, Elias J Jr, Dos Santos AC, Marques W Jr, Barreira AA. Involvement of the central nervous system in the chronic form of Chagas' disease. J Neurol Sci 2008;269:152-157.

12. Fazekas F, Niederkorn K, Schmidt R, et al. White matter signal abnormalities in normal individuals: correlation with carotid ultrasonography, cerebral blood flow measurements, and cerebrovascular risk factors. Stroke 1988;19:1285-1288.

13. Schmidt R, Fazekas F, Kleinert G, et al. Magnetic resonance imaging signal hyperintensities in the deep and subcortical white matter. A comparative study between stroke patients and normal volunteers. Arch Neurol 1992;49:825-827.

14. Vermeer SE, Hollander M, van Dijk EJ, Hofman A, Koudstaal PJ, Breteler MM;Rotterdam Scan Study. Silent brain infarcts and white matter lesions increase stroke risk in the general population: the Rotterdam Scan Study. Stroke 2003;34:1126-1129.

15. Medina M, Carrasco HA, Fuenmayor A, Medina A, Garcia MR. Diagnostico por metodos no invasivos de dano ventricular izquerdo incipiente en pacientes chagásicos - utilidad de la ecocardiografia y la fonomecanografia. Archiv Inst Cardiol Méx 1980;50:663-669.

16. Carrasco HA. Diagnóstico de dano miocardico en la enfermedad de Chagas. Textos de la Universidad de los Andes. Merida: Consejo de Publicationes de la Universidad de Los Andes, 1983.

17. Barbosa PRB, Barbosa J Filho, Cordovil I, Medeiros AB, Nadal J. Phase response of the spectral coherence between heart rate variability and ventricular repolarization duration in normal subjects. Comp Cardiol 2000;27:159-162. 
18. Baldwa VS, Ewing DJ. Heart rate response to Valsalva manouver: reproductibility in normals and relation to variation in resting heart rate in diabetics. Br Heart J 1977;39:641-644.

19. Task Force of the European Society of Cardiology and the North American Society of Pacing Electrophysiology. Heart rate variability: standards of measurement, physiological interpretation and clinical use. Circulation 1996;93:1043-1065.

20. Bigger JT, Fleiss JL, Steinman RC. Correlations among time and frequency domain measures of heart period variability two weeks after miocardial infarction. Am J Cardiol 1992;69:891-898.

21. Medei EH, Nascimento JH, Pedrosa RC, et al. Antibodies with beta-adrenergic activity from chronic chagasic patients modulate the
QT interval and M cell action potential duration. Europace 2008;10: 868-876.

22. Goin JC, Borda E, Leiros CP, Storino R, Sterin-Borda L. Identification of antibodies with muscarinic cholinergic activity in human Chagas' disease: pathological implications. J Auton Nerv Syst 1994;47:45-52.

23. Oliveira SF de, Pedrosa RC, Nascimento JH, Campos de Carvalho AC, Masuda MO. Sera from chronic chagasic patients with complex cardiac arrhythmias depress electrogenesis and conduction in isolated rabbit hearts. Circulation 1997;96:2031-2037.

24. Ribeiro AL, Moraes RS, Ribeiro JP, et al. Parasympathetic dysautonomia precedes left ventricular systolic dysfunction in Chagas disease. Am Heart J 2001;141:260-265. 